\title{
Fundo de Riqueza Soberana: uma análise sobre seus impactos no Brasil
}

Fernando Motta Correia ${ }^{*}$

Jedson César de Oliveira ${ }^{*}$

\section{Introdução}

A acumulação de saldos positivos no balanço de pagamentos no Brasil tem estimulado a discussão de um novo mecanismo de inserção do país junto ao mercado financeiro internacional com a criação de um Fundo de Riqueza Soberana. Com o acúmulo de reservas internacionais, a idéia da criação do Fundo Soberano seria valorizar o montante dessas reservas fazendo aplicações com retornos mais atraentes. A lógica de criar um fundo se dá pelo simples objetivo de aproveitar o momento favorável da economia guardando o excedente fiscal e de reservas em moeda estrangeira para o futuro. Um resultado imediato dessa estratégia seria o de transformar o país num importante acionista de companhias internacionais. Atualmente, as reservas brasileiras estão aplicadas em papéis soberanos de países ricos, aproximadamente $93 \%$ são compostas de títulos do tesouro norte-americano e 7\% em títulos do governo europeu.

A intenção do Brasil em diversificar suas reservas surge no momento em que vários países acumulam enormes quantidades de reservas internacionais. É preciso destacar que cada país tem um objetivo diferente para acumular reservas, e entre esses objetivos, dois deles se destacam: evitar a apreciação da moeda nacional, pois isso encarece as exportações e, conseqüentemente, reduz o saldo da balança comercial; e aumentar a rentabilidade de suas aplicações, pois os títulos do tesouro americano apesar de mais seguros possuem baixa remuneração.

Com a possibilidade de o Brasil entrar para o clube dos países criadores de fundos soberanos um terceiro objetivo pode estar surgindo. Isso porque tem sido levantada a hipótese de que o país utilize os reservas internacionais para investir em projetos de infraestrutura na América do Sul, visto que há uma restrição legal ao BNDES de financiar empresas estrangeiras.

De modo geral, os países que possuem um fundo soberano apresentam os seguintes requisitos:

\footnotetext{
* Doutorando em Desenvolvimento Econômico pela Universidade Federal do Paraná (UFPR). Endereço eletrônico: fmottabr@yahoo.com.br.

** Mestre em Desenvolvimento Econômico pela Universidade Federal do Paraná (UFPR). Endereço eletrônico: jecoli@,sociais.ufpr.br.
} 
i. São exportadores de recursos naturais não-renováveis e dependem da receita dessa exportação. Como exemplo, temos o Chile (cobre); Rússia, Noruega e países do Oriente Médio (petróleo) e Botsuana (diamante);

ii. Apresentam Superávit fiscal no conceito nominal;

iii. Possuem saldo elevado na Balança Comercial e no Balanço de Pagamentos e elevadas reservas cambiais. O país que melhor se enquadra nesse item é a China.

Dos três itens mencionados acima, o Brasil se aproxima mais do terceiro, pois tem apresentado um saldo importante no comércio internacional desde 2004 e um saldo pequeno no balanço de pagamentos, bem como um volume de reservas internacionais jamais visto aproximadamente US\$ 180 bilhões. No entanto, o fato do Brasil ainda apresentar déficit nominal da ordem de 2,3\% do PIB nos 12 meses encerrados em setembro torna difícil a tarefa de criar um fundo soberano, pois para que o país possa adquirir recursos financeiros para aplicação em ativos mais rentáveis ele ainda necessita emitir títulos públicos e pagar taxas de juros muito altas em relação aos outros países.

Uma das críticas mais ouvidas à idéia do governo levanta a hipótese de que o Brasil poderia estaria "remando contra a corrente" ao emitir títulos públicos para aplicar em investimentos do setor privado, pois o mercado financeiro faz exatamente o contrário ao adquirir recursos com baixíssimas taxas de juros, especialmente em países como o Japão, e comprar títulos do governo brasileiro considerado de baixo risco e alta remuneração. Ou seja, a decisão de investir em um fundo traria poucos benefícios e geraria um elevado custo. Uma alternativa seria aguardar a obtenção do "grau de investimento" para que os custos da captação do país sejam mais baixos.

Outro fator que pode dificultar a criação do fundo soberano diz respeito ao aspecto legal, pois para alguns analistas esses fundos são de natureza fiscal. Nesse caso, para criar o fundo o governo precisaria produzir superávits fiscais e, com os recursos, comprar reservas, em vez de simplesmente utilizar as existentes. Se o Banco Central do Brasil (BCB), que controla as reservas internacionais, as usasse para investir em ações ele estaria financiando o Tesouro Nacional, o que na prática é proibido pela Lei de Responsabilidade Fiscal (LRF). 


\section{Fundos soberanos existentes no mundo}

Os países ativos na criação dos fundos soberanos em sua maioria são aqueles que geram superávits nominais, principalmente oriundos das receitas de produção e exportação de petróleo. Dos 42 fundos soberanos existentes, 22 foram criados por grandes exportadores de petróleo, enquanto seis deles produzem diferentes commodities não-renováveis. Os 14 fundos restantes foram criados por economias industrializadas e fortemente superavitárias tanto na área fiscal quanto no balanço de pagamentos.

O gráfico a seguir ilustra o montante de recursos financeiros no mundo que estão influenciando a criação dos Fundos de Riqueza Soberana.

\section{Gráfico 1. Montante de Fundos de Riqueza Soberana por Modalidade}

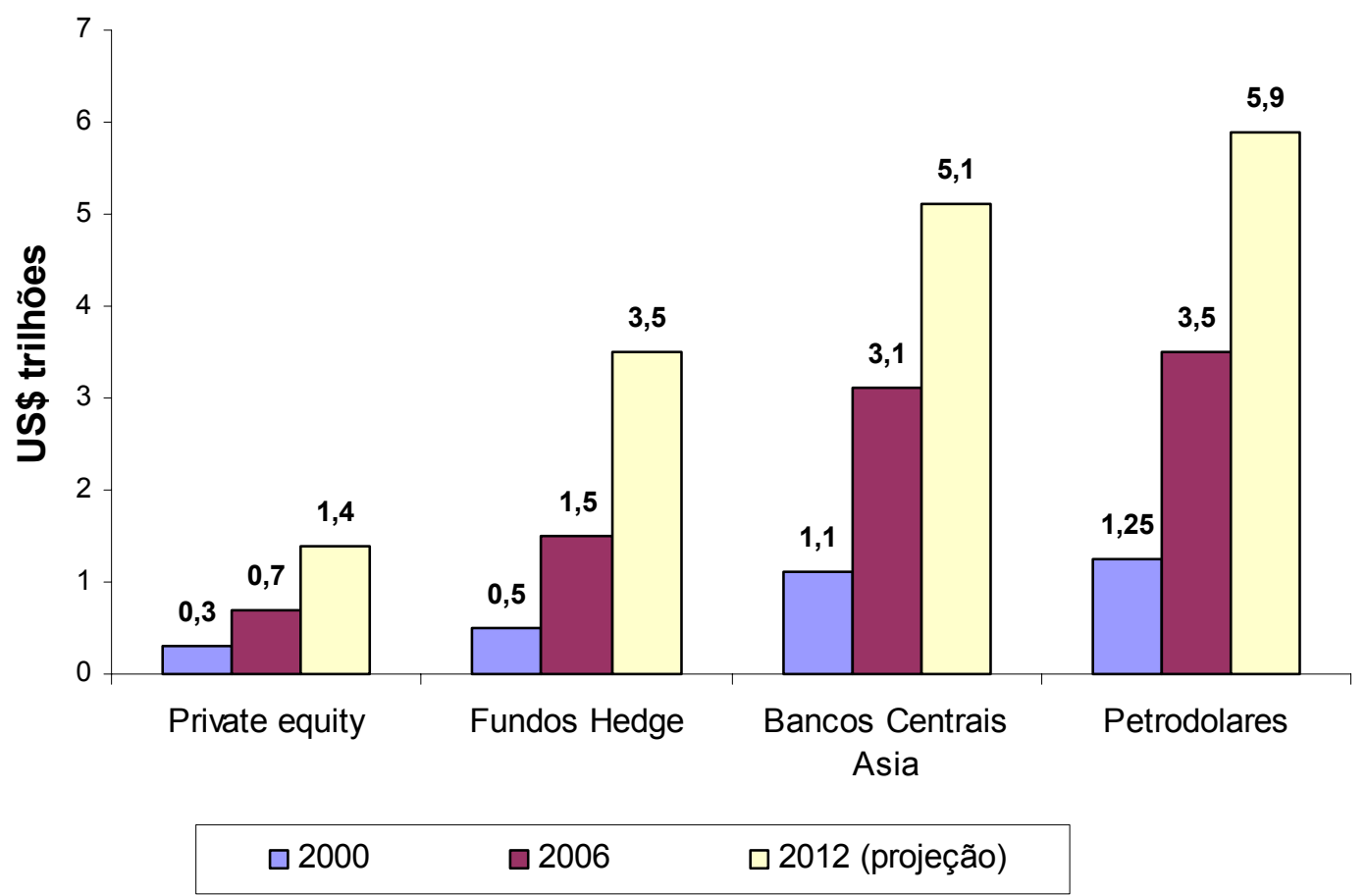

FONTE: McKinsey Global Institute.

Nota: Petrodolares a US\$ 50/ barril e Fundos de Hedge antes da alavancagem.

No caso brasileiro, afora o expressivo montante das reservas acumuladas, um outro fator de estímulo para a criação de tais fundos é a desvalorização do dólar frente as principais moedas internacionais. Haja vista que mais de $90 \%$ das reservas brasileiras estão aplicadas em títulos do tesouro americano, devido à significativa perda de valor da moeda americana, há um estímulo para o Brasil diversificar seus investimentos na tentativa de gerar um maior retorno das reservas acumuladas. 
Embora a perda de valor do dólar frente a outras importantes moedas seja um estímulo para a criação dos Fundos Soberanos, é válido destacar que não deverá ocorrer uma migração em massa desses mais de $90 \%$ de reservas brasileiras aplicados em títulos do tesouro americano na busca por retornos mais atraentes. O que se pretende é direcionar as reservas excedentes a partir de um montante que seria suficiente para zerar as dívidas externa e privada do país. Ou seja, para compor o Fundo Soberano, o Brasil deverá manter ainda uma posição conservadora em suas reservas num montante equivalente à sua dívida total e daí utilizar o excedente desse montante como recursos que irão compor o Fundo Soberano.

As vantagens que motivam a criação de um Fundo Soberano ultrapassam a simples fuga das perdas de rentabilidade geradas com a desvalorização do dólar. A possibilidade de criação desses fundos propicia a diversificação dos investimentos para maximizar retornos diluindo seus riscos.

Todavia, alguns mecanismos precisam ser mais discutidos a ponto de identificar possíveis inconsistências no gerenciamento do fundo. Em primeiro lugar uma das condições necessárias que estimula a criação de um Fundo Soberano é a possibilidade de transferir a poupança pública do presente para o futuro. Neste aspecto, o Brasil ainda não apresenta tal característica ao verificarmos déficits nominais nas contas públicas do país.

A tentativa de criar um fundo soberano para fazer investimentos no exterior e, assim, aproveitar a abundante liquidez de recursos no mercado financeiro internacional perpassa, antes de tudo, por uma base sólida nos fundamentos fiscais.

Se por um lado o Brasil pretende ingressar no seleto grupo de países que já desenvolvem operações a partir dos Fundos de Riqueza Soberana (ver quadro 1), cabe destacar que a sua longevidade nesse novo instrumento financeiro dependerá da sua conduta fiscal, na medida em que uma das motivações de entrada nesse mercado, como já mencionado, é a tentativa de captar um maior retorno das reservas acumuladas. 
Quadro 1. Fundos de Riqueza Soberana

\begin{tabular}{lcc}
\hline \multicolumn{1}{c}{ País } & $\begin{array}{c}\text { Ativos estimados } \\
\text { (bilhões de dólares) }\end{array}$ & Início \\
\hline Emirados Árabes Unidos & 875 & 1976 \\
Cingapura & 430 & 1974 \\
Arábia Saudita & 300 & n.d. \\
Noruega & 300 & 1996 \\
China & 300 & 2007 \\
Kuwait & 70 & 1953 \\
Austrália & 40 & 2004 \\
EUA (Alasca) & 35 & 1976 \\
Rússia & 32 & 2006 \\
Brunei & 30 & 1983 \\
Coréia do Sul & 20 & 2003 \\
\hline
\end{tabular}

Fonte: Morgan Stanley, março de 2007

Essa lógica não parece ter bases sólidas enquanto a política fiscal não sinalizar o controle tanto dos gastos correntes quanto do nível de endividamento público. O raciocínio é simples: se o pressuposto da geração de recursos para composição do fundo descarta a possibilidade de o governo elevar o superávit primário, o que possivelmente será verdade, no intuito de ampliar os recursos para alimentar o fundo, a alternativa de gerir tais recursos dependerá da compra de dólares com emissão de títulos, de igual modo como é feito com as reservas. O efeito desse mecanismo pode se refletir num resultado um tanto quanto deletério.

Num primeiro momento, devido ao perfil da dívida pública, concentrada em títulos de curto prazo e indexados a taxa Selic, a tentativa de criar recursos para alimentar o Fundo Soberano pode desencadear um processo de insolvência fiscal na medida em que o gerenciamento da dívida pública não afastou por completo choques externos. Vale destacar que o carregamento de uma dívida de curto prazo e indexada a taxa de juros não isenta o país dos choques externos suscetíveis nas economias emergentes. Um choque exógeno que proporcione uma desvalorização cambial ao contribuir para uma pressão inflacionária, gerando um aumento na taxa de juros, acaba aniquilando a política de redução da vulnerabilidade externa por meio da recompra da dívida externa e desdolarização da dívida 
pública, caso a mudança no perfil da dívida não seja para títulos de mais longo prazo e não indexados a taxa de juros de curto prazo.

Se a criação do fundo tem como justificativa a busca por um maior retorno das reservas acumuladas, qual o sentido de emitir títulos a uma taxa de juros elevada, como é a taxa Selic, para aumentar os recursos do Fundo Soberano? Uma vez que uma maior quantidade de títulos públicos com características do tipo LFT's, por exemplo, esteja sendo emitido para ampliar o volume de recursos para que o Fundo Soberano seja operacionalizado, tal mecanismo pode comprometer tanto a sustentabilidade da dívida pública como dificultar o alcance dos objetivos da política monetária em função dos choques externos que serão mais suscetíveis no país.

\section{Conclusões}

Em suma, para que o Brasil tenha mais chances de sucesso com respeito à criação de um fundo de riqueza soberana, inicialmente, seria fundamental que o governo implementasse um ajuste fiscal que limitasse o rápido crescimento das despesas correntes a uma taxa inferior ao do PIB, o que possivelmente abriria espaço para a redução das despesas financeiras, buscando alcançar o equilíbrio fiscal no conceito nominal, ou seja, quando se levam em consideração as despesas com juros da dívida pública. Aliado à obtenção do grau de investimento pelas agências de classificação de risco, o país teria todas as condições para diversificar o excedente gerado sem impactos negativos sobre o equilíbrio fiscal.

Se o país nesse momento deseja criar as condições necessárias para que no futuro tenhamos uma poupança que possa impulsionar ainda mais o crescimento econômico é preciso que algumas etapas sejam alcançadas. Ao contrário do que muitos analistas receitam, cortar despesas exige um esforço hercúleo e pode afetar o ritmo de crescimento justamente no momento em que o país começa a superar o processo Stop and Go vivido desde a criação do Plano Real em 1994, onde a economia apresenta arrancadas e freadas. O mais racional nesse momento seria manter o mesmo nível de despesas nominais ou limitar seu crescimento a taxas inferiores a do PIB dedicando mais atenção à melhoria da gestão dos recursos que proporcione maior produtividade para que no médio prazo o próprio crescimento econômico se encarregue de reduzir as despesas relativas ao PIB.

Quando o Brasil conseguir frear o crescimento acelerado das despesas sem que isso prejudique as demandas por segurança, educação e saúde de qualidade da população, bem como melhorar a infra-estrutura econômica, finalmente teremos condições de crescer de 
forma sustentada que permita aos agentes se preocuparem com o futuro, pois não se pode querer pensar em resolver os problemas do futuro sem resolver os problemas do presente. Em resumo, pode se afirmar que a criação do fundo de riqueza soberana é uma idéia extemporânea e fora dos propósitos para o caso brasileiro enquanto não resolvermos outros temas que põem em dúvida a questão da sustentabilidade fiscal frente aos desafios de uma economia mundial cada vez mais exigente e que não perdoa erros na condução da política econômica. 
